My first statement of the mode of identification ${ }^{2}$ therefore still stands.

\section{I. KaTZIN*}

Chemistry Division,

Atomic Energy Research Establishment, Harwell.

* Exchange Fellow from Argonne National Laboratory, Lemont, Illinois

1 Lingafelter, F. C., Nature, 182, 1730 (1958).

Katyin, L. I., Nature, 182, 1013 (1958)

s Ballhausen, C. J., Dan. Mat. Fys. Medd, 29, No. 8 (1955).

IT would appear quite possible that the disappearance of the 400-m $\mu$ peak is indicative of tetrahedral co-ordination of nickel(II), and I have no argument with this criterion. My communication was prompted by Katzin's apparent conclusion concerning the con. figuration of the blue compounds studied by Lifshitz, Bos and Dijkema on the basis of visual colour alone.

\section{E. C. Lingafelter}

Department of Chemistry,

University of Washington, Seattle 5.

\section{A Colour Reaction for Thiosulphinates}

Investigations of the chemistry of the thiolsulphinates, both synthetic and of natural provenance, would be aided if a rapid colorimetric test for these compounds were available. Aliphatic thiolsulphinates can be characterized, in part at least, by reaction with thiamine $^{1}$ or with cysteine ${ }^{2}$ to yield crystalline derivatives; but these methods do not generally distinguish thiolsulphinates from thiolsulphonates, since the latter compounds will also react with these reagents. The addition of sodium nitroprusside ${ }^{3}$ solution followed by base will yield orange to red colours in the presence of aliphatic thiolsulphinates or thiolsulphonates. This procedure has found application in paper chromatography ${ }^{3}$ in investigations of the formation of thiolsulphinates in plants of the genus Allium. In our experience, the colour, however, is very fugitive and is apparently not produced by some aromatic thiolsulphinates.

We have found that addition of a solution of $\mathrm{N}$-ethylmaleimide in isopropyl alcohol followed by potassium hydroxide in the same solvent to thiolsulphinates yields pink to red colours. Thiolsulphinates can therefore be distinguished from disulphides, which remain colourless. This is an extension of the colour test for thiols reported by Benesch and Benesch et $a l .{ }^{4}$. The conditions for the test are essentially the same as described for thiols by these authors. The maleimide derivative and potassium hydroxide are used in dry isopropyl alcohol solutions, $0.05 M$ and $0.25 M$, respectively, and the $\mathrm{N}$-ethyl maleimide is used in a very large molar excess over the thiolsulphinate. The reaction may be applied on paper, in which case the paper containing a thiolsulphinate spot is first dipped in the $\mathrm{N}$-ethyl maleimide solution, dried for 5-10 min., and is then dipped in the potassium hydroxide solution. A pink spot develops immediately where thiolsulphinate is present. The test may also be performed in solution in colorimeter tubes and absorbance or per cent transmittance measured.

For colorimetric analysis, $1 \mathrm{ml}$. of $0.05 M \mathrm{~N}$-ethyl maleimide reagent is added to $0 \cdot 5-5$ umoles of thiolsulphinate in $1 \mathrm{ml}$. of isopropyl alcohol and then
$1 \mathrm{ml}$. of $0.25 M$ potassium hydroxide solution is immediately added. Intensity of colour is conveniently measured at $5150 \mathrm{~A}$. (absorption maximum 5100 A.). The colour fades rapidly during the first 3 min. and then diminishes at a slower rate. Moderately reproducible results are obtained if the absorbance is measured at a specified time between 10 and $18 \mathrm{~min}$. after the addition of alkali and compared with standard curves obtained from measurements of pure compounds. The intensity of colour varies somewhat with different thiolsulphinates. The reaction has been applied to several synthetic thiolsulphinates $(R \mathrm{~S}(\mathrm{O}) \mathrm{S} R)$ where $R$ is phenyl, $p$-tolyl, ethyl, $n$-propyl, and 2-propenyl. The purity of these compounds was established by infra-red analysis. An allicin isolate from garlic and a lowtemperature vacuum distillate from a fresh onion concentrate (both of which were shown to be free of thiols) responded to the test. The reaction is sufficiently sensitive just to detect $5 \times 10^{-2}$ umole thiolsulphinate $/ \mathrm{ml}$. of solution.

In certain cases, the reaction will distinguish thiolsulphinates $(R \mathrm{~S}(\mathrm{O}) \mathrm{S} R$ ) not only from disulphides but also from thiolsulphonates $\left(R \mathrm{SO}_{2} \mathrm{~S} R\right)$. For example, $p$-tolyl $p$-toluene thiolsulphonate and phenyl benzene thiolsulphonate give no appreciable colour (indistinguishable from the background due to the reagents). Ethyl ethane thiolsulphonate produces a very faint colour, approximately 2 per cent of the intensity of the colour of the corresponding thiolsulphinate and $n$-propyl- $n$-propane thiolsulphonate gives a colour approximately 14 per cent as intense as that of the propyl thiolsulphinate. On the other hand, the colour produced by methyl methane thiolsulphonate is a third as strong as that of ethyl ethane thiolsulphinate (the corresponding methyl derivative was not available for comparison), although the compound was shown to be free of thiolsulphinate by infra-red analysis. The relatively high colour value given by the propyl thiolsulphonate compared with the corresponding ethyl compound may be a result of small amounts of thiolsulphinate as impurity in the former. Other classes of compounds responding to the test are thiols and thiolesters as shown by Benesch and Benesch et al. ${ }^{4}$, and S-alkyl isothiouronium bromides and aromatic sulphinic acids. In the spectrophotometric method for determining thiols ${ }^{5}$ with $\mathrm{N}$-ethylmaleimide in phosphate buffer, the thiol adds to the double bond of the maleimide as measured by the decrease in absorbance at $3000 \mathrm{~A}$. In isopropyl alcohol, however, no addition is observed with aliphatic thiols or thiolsulphinates. Whether the addition of base produces a rapid addition to the double bond followed by other colour-forming reactions or whether the reactions follow a different course is not known.

JOHN F. CARSON

Francis F. Wong

Western Regional Research Laboratory, Albany, California. April 21.

${ }^{1}$ Matsukawa, T., Kawasaki, H., Iwatsu, T., and Yurigi, S., J. Vitominol. (Japan), 1, 13 (1954). Matsukawa, T., Proc. Japan Acad.. 28, 146 (1952)

${ }^{2}$ Small, L. D., Bailey, J. H. and Cavallito, C. J., J. Amer. Chem. Soc., 69, i710 (1947).

${ }^{3}$ Fujiwara, M., Yoshimura, M., and Tsuno, S., J. Biochem. (Japan), 42, 591 (1955).

Benesch, R., Benesch, R. E., Gutcho, M., and Laufer, L., Science, 123, 981 (1956). "Alexander, N. M., Anal. Chem , 30, 1292 (1958). Roberts, E., and
Rouser, G. ibid., 30, 1291 (1958). 